TITLE:

\title{
Mitochondrial DNA Population Structure of the White-Spotted Charr (Salvelinus leucomaenis) in the Lake Biwa Water System
}

\section{AUTHOR(S):}

Kikko, Takeshi; Kuwahara, Masayuki; Iguchi, Kei'ichiro; Kurumi, Seiji; Yamamoto, Shoichiro; Kai, Yoshiaki; Nakayama, Kouji

\section{CITATION:}

Kikko, Takeshi ...[et al]. Mitochondrial DNA Population Structure of the White-Spotted Charr (Salvelinus leucomaenis) in the Lake Biwa Water System. Zoological Science 2008, 25(2): 146-153

\section{ISSUE DATE:}

2008-02

URL:

http://hdl.handle.net/2433/108573

\section{RIGHT:}

(c) 日本動物学会 / Zoological Society of Japan 


\title{
Mitochondrial DNA Population Structure of the White-Spotted Charr (Salvelinus leucomaenis) in the Lake Biwa Water System
}

\author{
Takeshi Kikko $^{1 *}$, Masayuki Kuwahara ${ }^{2}$, Kei'ichiro Iguchi $^{3}$, \\ Seiji Kurumi ${ }^{4}$, Shoichiro Yamamoto ${ }^{5}$, Yoshiaki Kai ${ }^{6}$ \\ and Kouji Nakayama ${ }^{7}$ \\ ${ }^{1}$ Samegai Trout Farm, Shiga Prefectural Fisheries Experimental Station, Kaminyu, Maibara, \\ Shiga 521-0033, Japan \\ ${ }^{2}$ Lake Biwa Museum, 1091 Oroshimo, Kusatsu, Shiga 525-0001, Japan \\ ${ }^{3}$ National Research Institute of Fisheries Science, Fisheries Research \\ Agency, Komaki 1088, Ueda, Nagano 386-0031, Japan \\ ${ }^{4}$ Imazu Junior High School, Hirokawa 924, Takashima, Shiga 520-1611, Japan \\ ${ }^{5}$ National Research Institute of Fisheries Science, Fisheries Research Agency, \\ Nikko, Tochigi 321-1661, Japan \\ ${ }^{6}$ Maizuru Fisheries Research Station, Field Science Education Research \\ Center, Kyoto University, Nagahama, Maizuru, Kyoto 625-0086, Japan \\ ${ }^{7}$ Division of Applied Biosciences, Graduate School of Agriculture, \\ Kyoto University, Kyoto 606-8502, Japan
}

\begin{abstract}
A phylogeographic analysis of mitochondrial DNA sequences was performed in order to elucidate the origin, dispersal process, and genetic structure of white-spotted charr in the Lake Biwa water system. Two haplotypes were most common in the Lake Biwa water system, and were also common in the adjacent inlet rivers of the Sea of Japan. These results suggest that in the glacial periods of the Pleistocene, white-spotted charr dispersed into the northern inlet rivers of Lake Biwa from adjacent inlet rivers of the Sea of Japan by watershed exchanges, colonizing the whole of the Lake Biwa water system. Mitochondrial DNA diversity contrasted sharply between the western and eastern parts of the system, suggesting that the populations in the western part might be more reduced than those in the eastern part in relation to the smaller habitat size. The high overall $F_{\mathrm{ST}}$ estimate $(0.50)$, together with pairwise comparisons of $F_{\mathrm{ST}}$, indicated significant genetic divergence between populations due to isolation and small population size. Hierarchical analysis (AMOVA) also showed that genetic variation was more pronounced among regions $(28.39 \%)$ and among populations within regions $(47.24 \%)$ than within populations $(24.37 \%)$. This suggests that each population in and around the Lake Biwa water system should be treated as a significant unit for conservation and management.
\end{abstract}

Key words: Salvelinus leucomaenis, phylogeography, mitochondrial DNA, dispersal, bottleneck

\section{INTRODUCTION}

The white-spotted charr, Salvelinus leucomaenis, is a cold-water adapted fish distributed throughout Far Eastern Asia (Kawanabe, 1989). The systematics of the species and process of population formation over the whole distributional range have been discussed by many authors, mainly on the basis of external color pattern (reviewed in Kawanabe,

\footnotetext{
${ }^{*}$ Corresponding author. Phone: +81-77-528-3872;

Fax : +81-77-528-4885;

E-mail : kikkou-takeshi@pref.shiga.Ig.jp

† Present address: Fisheries Management Division, Department of Agriculture and Fisheries, Shiga Prefectural Government, 4-1-1, Kyomachi, Otsu, Shiga 520-8577, Japan

doi:10.2108/zsj.25.146
}

1989). However, the evolutionary history of the charr remains equivocal due to its highly variable external color pattern among and within local populations (Yamamoto et al., 2000; Nakamura, 2003). Recently, Yamamoto et al. (2004a) examined mitochondrial DNA (mtDNA) sequences from 50 populations of the white-spotted charr throughout most of its range in Japan and suggested that extensive dispersal occurred through seaward migration during glacial periods, followed by the persistence of populations in rivers during interglacial periods. This process would have occurred repeatedly across time and space, with extensive secondary contact occurring under the fluctuating climatic conditions of the Pleistocene.

Four subspecies of white-spotted charr have been recognized across the species range, based mainly on differ- 
ences in the body spot pattern (Hosoya, 2002). In the Lake Biwa water system, near the southern limit of the distribution range, Naruse and Yoshiyasu (1983) concluded that S. I. japonicus is distributed in the eastern basin and S. I. pluvius in the western basin, on the basis of differences in body spot pattern, and suggested that the former colonized the eastern basin across the watershed from inlet rivers of the Pacific Ocean and the latter colonized the western basin across the watershed from inlet rivers of the Sea of Japan. However, recent genetic studies have revealed that there is only limited congruence between the mtDNA phylogeographic pattern and the distributions of the four subspecies based on the body spot patterns described by Hosoya (2002). Furthermore, genetic variation was far more pronounced among local populations within subspecies than among subspecies (i.e., among discrete regions; Yamamoto et al., 2004a). Therefore, the origin of the populations of the Lake Biwa water system proposed by Naruse and Yoshiyasu (1983) should be reconsidered.

Recently, Yamamoto et al. (2004a) reported that the populations in the Lake Biwa water system may have originated from inlet rivers of the Sea of Japan; however, these authors sequenced only one population of the Lake Biwa water system (Ane River in the eastern part of the system) and failed to collect specimens from adjacent river systems. Therefore, the possibility of the origin of the populations of white-spotted charr of the Lake Biwa water system from the Pacific side, proposed by Naruse and Yosiyasu (1983), was not addressed by their genetic analysis, and details of the process of dispersal to the Lake Biwa water system remain unclear.

The process of formation of populations within the Lake Biwa water system also remains unclear because of the limited congruence between the mtDNA phylogeographic patterns and the distributions of the four subspecies (Yamamoto et al., 2004a). Recently, white-spotted charr in the system were listed as under potential threat in Shiga Prefecture (Fujioka, 2005). Kikko et al. (2008a) examined seven populations of white-spotted charr in the Lake Biwa water system by AFLP analysis and found that each local population among rivers was genetically differentiated. However, no difference were detected between the eastern and western basins; rather, the results suggested that the whitespotted charr was subdivided among high altitude areas in the Lake Biwa water system. The dispersal pattern within the Lake Biwa water system remained unclear, because AFLP could not reveal the gene genealogies among the populations.

In this paper, we sequenced the mitochondrial cytochrome $b$ region from specimens collected from the Lake Biwa water system and the adjacent river systems where the white-spotted charr occurs naturally, with the aim of clarifying 1) the origin of the Lake Biwa populations, focusing on possibilities both from the Sea of Japan side and the Pacific side, and 2) the dispersal process within the Lake Biwa water system.

\section{MATERIALS AND METHODS}

\section{Sample collection}

Sixteen populations of white-spotted charr (195 individuals) were sampled by electrofishing or bait fishing between 2002 and
2004 (Fig. 1; Table 1). The white-spotted charr is not distributed in the Yodo River system but is distributed in high-altitude areas (Nosaka, Hira, Ibuki, Suzuka Mts.; Fig. 1) in the Lake Biwa water system. Furthermore, the charr is not distributed on the opposite flanks of the Hira and Suzuka Mts. in the Lake Biwa system but is distributed on the opposite flanks of the Nosaka and Ibuki Mts. (Imanishi, 1967).

We examined the comprehensive geographic distribution pattern of mtDNA sequence polymorphism in the 16 wild populations of charr in the four mountainous areas (Nosaka, Hira, Ibuki, Suzuka Mts.) and adjacent inlet rivers of the Sea of Japan and the Pacific Ocean, to assess details of its dispersal and genetic structure in the Lake Biwa water system. Sampling was conducted in upstream reaches above dams or waterfalls, so as to exclude any stocked fish. We found no records that charr have ever been artificially released in the sampling reaches, so we considered all caught individuals to be native.

\section{DNA data analysis}

We took the adipose fin of each specimen and preserved it in $99.5 \%$ ethanol for DNA extraction, and released all specimens within the same sampling reach. Total genomic DNA was extracted from the fins by using the DNeasy Tissue Kit (Qiagen, Hilden, Germany), following the manufacturer's protocol. Partial sequences of the mitochondrial cytochrome $b$ gene (Cyt $b$ ) were determined, because this gene shows appropriate variation and was employed in previous studies (Yamamoto et al., 2004a; Kubota et al., 2007). For data analysis, the nucleotide sequences of published data (Yamamoto et al., 2004a) were also included (DDBJ, EMBL, and Gene Bank accession number $A B$ 111031). DNA sequences were aligned with the multiple sequence editor CLUSTAL W (Thompson et al., 1994) to identify nucleotide variation, from which haplotypes were defined.

Phylogenetic relationships among the haplotypes were constructed by maximum parsimony (MP) analyses using PAUP* 4.0b10 (Swofford, 2000). Maximum parsimony analyses were performed using heuristic searches with the tree bisection-reconnection branch swapping algorithm. Bootstrap analysis (Felsenstein, 1985) of 1,000 pseudoreplicates was used to measure support of the resulting topologies. Genetic variation within each population was quantified by haplotype diversity $(h)$ and nucleotide diversity $(\pi)$ (Nei, 1987) using Arlequin version 3.01 (Excoffier et al., 2005). Genetic differentiation among the populations was assessed by the pairwise fixation index $\left(F_{\mathrm{ST}}\right)$ as defined by Wright (1969), also using Arlequin 3.01 , the significance of the $F_{S T}$ values being tested by 100,000 random permutations. The significance of the genetic heterogeneity among populations and regions was assessed with AMOVA (Excoffier et al., 1992) using a predictive model of regional partitioning to test the phylogeographic structure. Populations were categorized into the four regions on the basis of the four mountain areas (Nosaka, Hira, Ibuki, Suzuka Mts.), because the distribution of white-spotted charr is restricted to higher altitudes in the southern regions of its range (Nakano et al., 1996; Kikko et al., 2008a).

\section{RESULTS}

\section{Phylogenetic relationships and geographical distribu- tion of haplotypes}

Yamamoto et al. (2004a) sequenced the $557 \mathrm{bp}$ of the Cyt $b$ gene and identified 29 haplotypes (Hap-1 to Hap-29). We determined a 525-bp nucleotide sequence for 195 whitespotted charr individuals (Table 2) and combined our data with that obtained by Yamamoto et al. (2004a). Among the 525 bp of Cyt $b$ sequenced from 195 individuals in this study and the 29 haplotypes of Yamamoto et al. (2004a), a total of $31(5.9 \%)$ nucleotide positions were polymorphic, of 


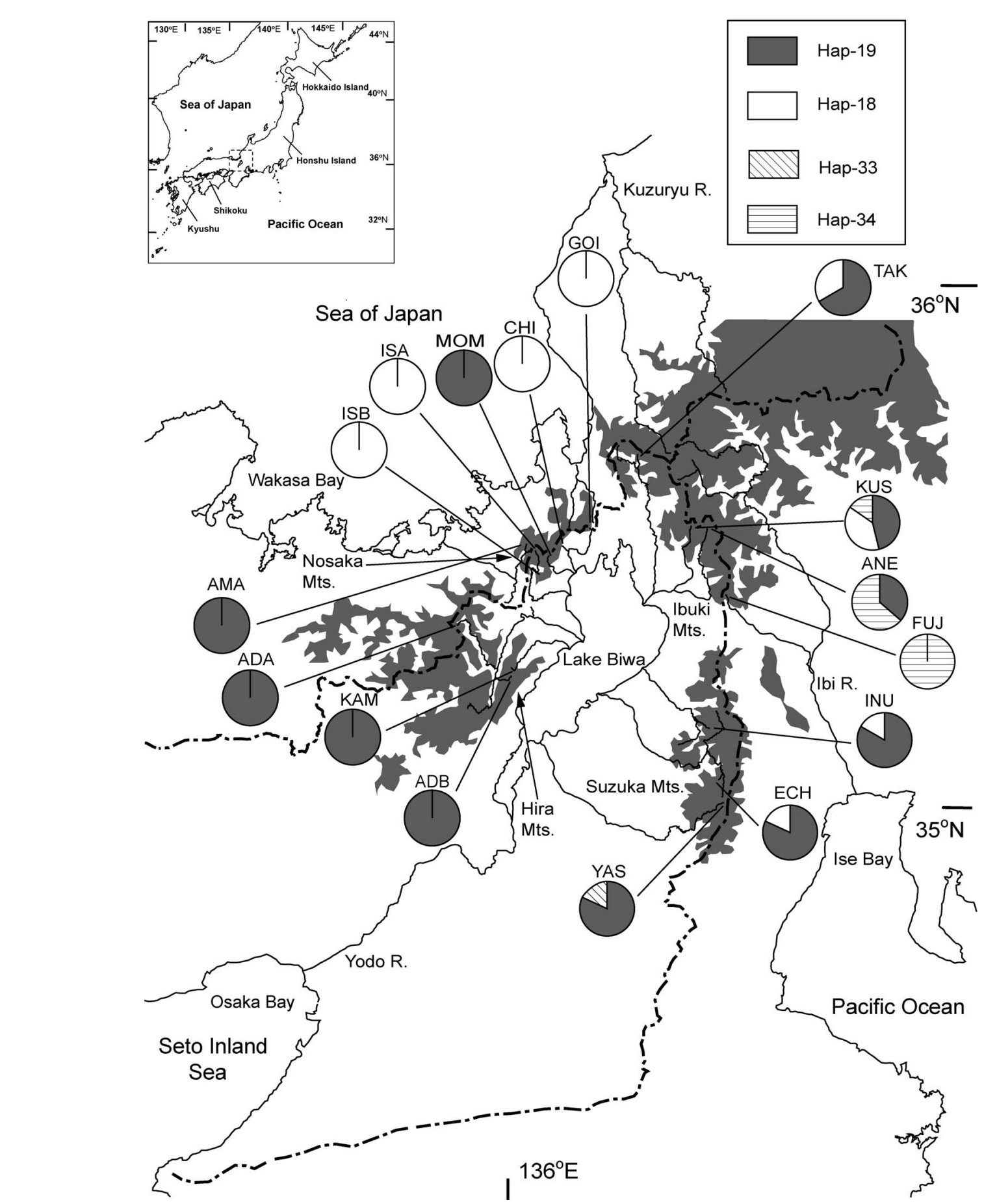

Fig. 1. Geographical locations of the sampling localities and distribution of mtDNA haplotypes. Haplotypes are shaded according to phylogenetic relationship (see Fig. 2.). Pie charts indicate the relative frequencies of these haplotypes. Details of the sampling localities with a list of abbreviations and sample sizes are provided in Table 1. The broken lines indicate major watersheds. The shaded areas of the map represent the four mountain ranges (Nosaka, Hira, Ibuki, Suzuka Mts.) higher than $500 \mathrm{~m}$ in altitude.

which 26 (84\% of variable sites) were in third-codon positions, three $(10 \%)$ in first positions, and two $(6 \%)$ in second positions. Due to the shorter sequences in our study, Hap3, Hap-19, and Hap-25 of Yamamoto et al. (2004a) could not be distinguished from those termed as Hap-5, Hap-17, and Hap-23, respectively. Accordingly, we redefined 26 haplotypes from the 29 haplotypes of Yamamoto et al. (2004a). We found two novel haplotypes that we numbered Hap-33 and Hap-34, because Kubota et al. (2007) had reported three additional haplotypes (Hap-30, 31, 32) from the upper Tone River drainage.

MP analysis of the 26 redefined haplotypes, the two new haplotypes, and two outgroup haplotypes (Dolly Varden and bull charr) yielded three equally parsimonious trees, supported by a high consistency index $(\mathrm{Cl}=0.903)$. The three trees differed only in the positions of Hap-9, Hap-12, Hap- 
Table 1. Specimens of white-spotted charr used for the mtDNA analysis.

\begin{tabular}{|c|c|c|c|}
\hline \multicolumn{2}{|l|}{ Locality } & \multirow{2}{*}{$\begin{array}{c}\text { Date of } \\
\text { collection }\end{array}$} & \multirow{2}{*}{$\begin{array}{l}\text { Number of } \\
\text { specimens }\end{array}$} \\
\hline Population & Abbreviation & & \\
\hline \multicolumn{4}{|c|}{ The western part of the Lake Biwa water system } \\
\hline Chinai River & $\mathrm{CHI}$ & Jul. 2004 & 11 \\
\hline Momose R. & MOM & Jun. 2002 & 14 \\
\hline A population of Ishida . $^{*}$ & ISA & May 2003 & 13 \\
\hline B population of Ishida R. & ISB & Feb. 2004 & 12 \\
\hline A population of Ado R.* & ADA & May 2003 & 13 \\
\hline B population of Ado R. & ADB & Mar. 2004 & 13 \\
\hline Kamo R. & KAM & Mar. 2004 & 13 \\
\hline \multicolumn{4}{|c|}{ The eastern part of the Lake Biwa water system } \\
\hline Takatoki R.* & TAK & Jun. 2003 & 12 \\
\hline Kusano R. & KUS & Sep. 2003 & 13 \\
\hline Ane R.* & ANE & Jun. 2002 & 11 \\
\hline Inukami R. & INU & Sep. 2003 & 11 \\
\hline Echi R. & $\mathrm{ECH}$ & Jun. 2002 & 12 \\
\hline Yasu R.* & YAS & May 2003 & 12 \\
\hline \multicolumn{4}{|l|}{ The inlet rivers of Sea of Japan } \\
\hline Amasu R. (Kita River system) & AMA & Jun. 2004 & 12 \\
\hline Goi R. (Shouno R. system) & GOI & Jul. 2004 & 10 \\
\hline \multicolumn{4}{|l|}{ The inlet river of Pacific Ocean } \\
\hline Fujiko R. (Ibi R. system) & FUJ & Jul. 2004 & 13 \\
\hline
\end{tabular}

* Samples from the previous study by Kikko et al. (2008a)

Table 2. Mitochondrial sequence variation in $525 \mathrm{bp}$ of Cyt $b$ sequenced from 195 white-spotted charr individuals in this study. Haplotype designations refer to the nomenclature used in Yamamoto et al. (2004a). Nucleotide position numbers correspond to the nucleotide sequence of Hap-1, available from DDBJ, EMBL, and Gene Bank (accession number AB111031). New haplotypes detected in this study are in bold.

\begin{tabular}{lccccccccc}
\cline { 2 - 7 } Haplotype & 31 & 103 & 184 & 211 & 214 & 254 & 280 & 313 & 328 \\
\hline Hap-1 & T & C & G & A & T & C & A & C & G \\
Hap-18 & C & A & A &. & C & T &. & T & A \\
Hap-19,17* &. & A & A &. & C & T &. &. & A \\
Hap-33 &. & A & A &. & C & T & G &. & A \\
Hap-34 & C & A & A & C & C & T &. & T & A \\
\hline
\end{tabular}

*Hap 19 is identical to Hap 17 in Yamamoto et al. (2004a).

28, and Hap-29. These haplotypes were not detected in the Lake Biwa water system or around the system in our study. Thus, only one of the three equally parsimonious trees is shown in Fig. 2. Two additional haplotypes (Hap-33, Hap34) as well as Hap-18 are mutational derivatives of Hap-19, differing from Hap-19 by one to three nucleotide changes.

Four haplotypes (Hap-18, 19, 33, 34) were recognized from the 195 individuals of the Laka Biwa populations. Pairwise sequence divergence among the four haplotypes detected in the 16 wild populations ranged from 0.19 $0.76 \%$, with a mean of $0.44 \%$. The most common haplotype, Hap-19, was widespread throughout the Lake Biwa water system, detected from the northernmost Takatoki River population (TAK) to the southernmost Yasu River population (YAS). Only Hap-19 was observed in the populations of the Momose River (MOM), both the $A$ and $B$ populations of the Ado River (ADA, ADB), the Kamo River (KAM) in the west- ern part of the Lake Biwa water system, and the Amasu River (AMA) flowing into the Sea of Japan. The second most common haplotype, Hap-18, was detected mainly in the northern inlet rivers of Lake Biwa. Only Hap-18 was observed in the populations of the Chinai River $(\mathrm{CHI})$, both the $A$ and $B$ populations of the Ishida River (ISA, ISB) in the western part of the Lake Biwa water system, and the Goi River (GOI) flowing into the Sea of Japan. Hap-19 cooccurred with Hap-18 in the four populations in the eastern part of the Lake Biwa water system. The third most common haplotype, Hap-34, was confined to three populations from the eastern and western flanks of the lbuki Mts., and was fixed in the Fujiko River (FUJ) flowing into the Pacific Ocean. Hap-33 was detected only in the Yasu River (YAS), the southernmost population in the Lake Biwa water system.

\section{Genetic variation within local populations}

The number of observed haplotypes within populations ranged from one to three in the 16 wild populations (Fig. 1; Table 3). The intrapopulation pattern of genetic diversity varied within each geographical assemblage. All populations in the western part of the Lake Biwa water system, including two populations in rivers flowing into the Sea of Japan, were monomorphic ( $h=0, \pi=0 \%)$. In the eastern part of the Lake Biwa water system, relatively higher diversity indices ( $h=0.485-0.590, \pi=0.185-0.291 \%$ ) were found in the lbuki Mts., whereas those in the Suzuka Mts. were low $(h=0.167-$ $0.327, \pi=0.032-0.173 \%)$.

\section{Genetic differentiation among populations}

The overall estimates of $F_{\mathrm{ST}}$ were high, with a mean over all pairs of 0.50 . Estimates of $F_{\mathrm{ST}}$ differed significantly from zero among about half of pairwise comparisons (55 out of the 120), indicating the presence of genetic differentiation 


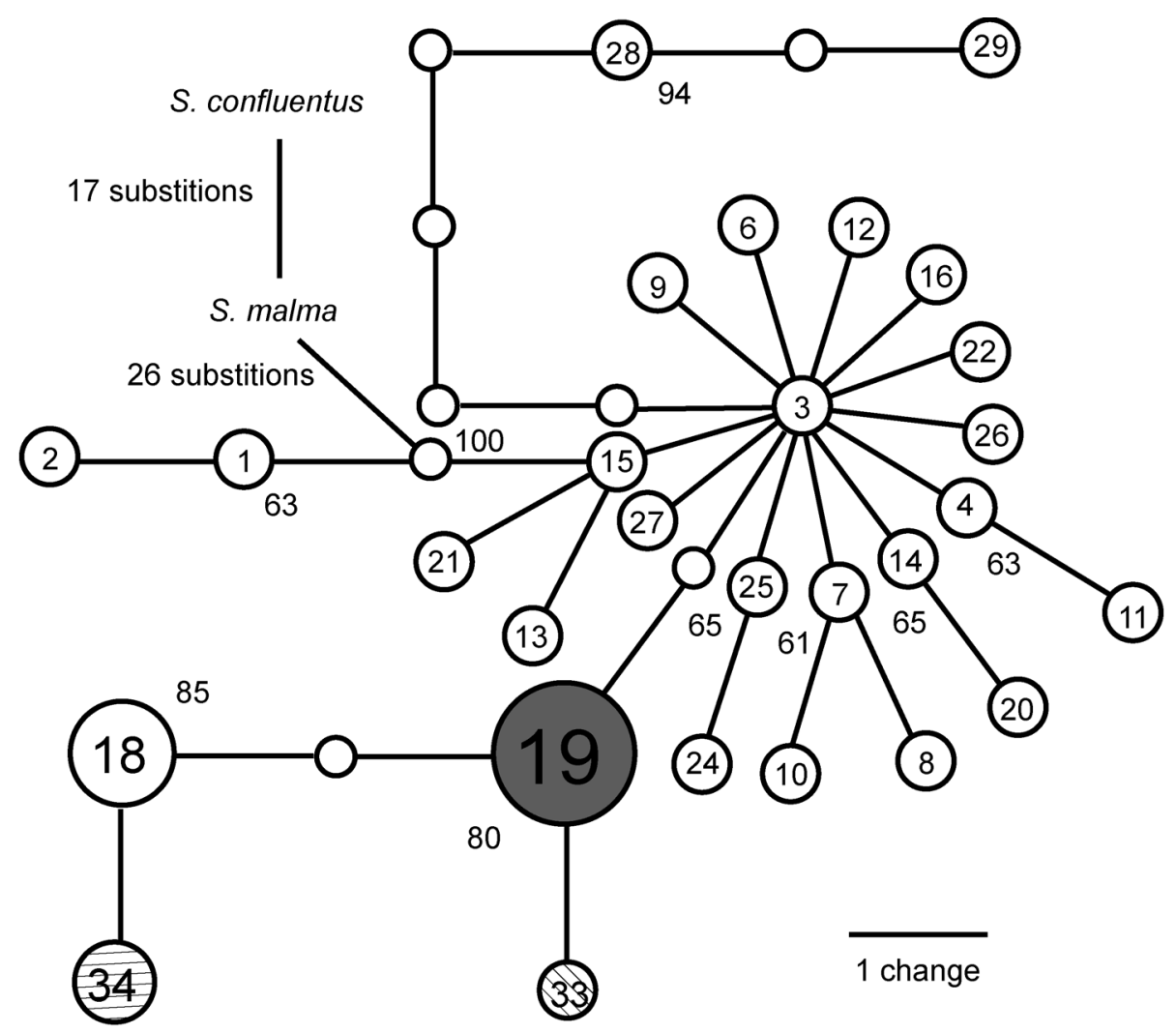

Fig. 2. One of three most parsimonious trees of haplotypes detected from the 16 wild populations of white-spotted charr in this study, and from 50 other populations of white-spotted charr and two outgroup species, Dolly Varden (Salvelinus malma) and bull charr ( $S$. confluentus), in Yamamoto et al. (2004a). Haplotype abbreviations correspond to those listed in the Appendix of Yamamoto et al. (2004a) and Table 3 in this study. Bootstrap values from 1,000 pseudoreplicates are shown near nodes. Circle sizes reflect haplotype frequencies.

Table 3. Distribution of mtDNA Cyt $b$ region haplotypes and haplotype diversity $(h)$, and nucleotide diversity $(\pi)$ of the studied populations of white-spotted charr.

\begin{tabular}{|c|c|c|c|c|c|c|c|c|}
\hline \multirow[b]{2}{*}{ Locality* } & \multirow{2}{*}{$\begin{array}{l}\text { Number of } \\
\text { specimens }\end{array}$} & \multicolumn{4}{|c|}{ Number of individuals with haplotype } & \multirow{2}{*}{$\begin{array}{l}\text { Number of } \\
\text { haplotypes }\end{array}$} & \multirow{2}{*}{$\begin{array}{l}\text { Haplotype diversity } \\
\qquad h \pm S D\end{array}$} & \multirow{2}{*}{$\begin{array}{l}\text { Nucleotide diversity } \\
\qquad \pi \pm S D\end{array}$} \\
\hline & & 18 & 19 & 33 & 34 & & & \\
\hline \multicolumn{9}{|c|}{ The western part of the Lake Biwa water system } \\
\hline $\mathrm{CHI}$ & 11 & 11 & 0 & 0 & 0 & 1 & $0.000 \pm 0.000$ & $0.00000 \pm 0.00000$ \\
\hline MOM & 14 & 0 & 14 & 0 & 0 & 1 & $0.000 \pm 0.000$ & $0.00000 \pm 0.00000$ \\
\hline ISA & 13 & 13 & 0 & 0 & 0 & 1 & $0.000 \pm 0.000$ & $0.00000 \pm 0.00000$ \\
\hline ISB & 12 & 12 & 0 & 0 & 0 & 1 & $0.000 \pm 0.000$ & $0.00000 \pm 0.00000$ \\
\hline ADA & 13 & 0 & 13 & 0 & 0 & 1 & $0.000 \pm 0.000$ & $0.00000 \pm 0.00000$ \\
\hline ADB & 13 & 0 & 13 & 0 & 0 & 1 & $0.000 \pm 0.000$ & $0.00000 \pm 0.00000$ \\
\hline KAM & 13 & 0 & 13 & 0 & 0 & 1 & $0.000 \pm 0.000$ & $0.00000 \pm 0.00000$ \\
\hline \multicolumn{9}{|c|}{ The eastern part of the Lake Biwa water system } \\
\hline TAK & 12 & 4 & 8 & 0 & 0 & 2 & $0.485 \pm 0.106$ & $0.00185 \pm 0.00152$ \\
\hline KUS & 13 & 5 & 6 & 0 & 2 & 3 & $0.590 \pm 0.122$ & $0.00249 \pm 0.00187$ \\
\hline ANE & 11 & 0 & 4 & 0 & 7 & 2 & $0.509 \pm 0.101$ & $0.00291 \pm 0.00213$ \\
\hline INU & 11 & 2 & 9 & 0 & 0 & 2 & $0.327 \pm 0.153$ & $0.00125 \pm 0.00117$ \\
\hline $\mathrm{ECH}$ & 12 & 2 & 10 & 0 & 0 & 2 & $0.303 \pm 0.148$ & $0.00173 \pm 0.00145$ \\
\hline YAS & 12 & 0 & 10 & 2 & 0 & 2 & $0.167 \pm 0.134$ & $0.00032 \pm 0.00052$ \\
\hline \multicolumn{9}{|c|}{ The inlet rivers of Sea of Japan } \\
\hline AMA & 12 & 0 & 12 & 0 & 0 & 1 & $0.000 \pm 0.000$ & $0.00000 \pm 0.00000$ \\
\hline GOI & 10 & 10 & 0 & 0 & 0 & 1 & $0.000 \pm 0.000$ & $0.00000 \pm 0.00000$ \\
\hline \multicolumn{9}{|c|}{ The inlet river of Pacific Ocean } \\
\hline FUJ & 13 & 0 & 0 & 0 & 13 & 1 & $0.000 \pm 0.000$ & $0.00000 \pm 0.00000$ \\
\hline
\end{tabular}

\footnotetext{
* Abbreviations correspond to Table 1.
} 
Table 4. Pairwise estimates of Fst (below diagonal) and statistically significant pairs (above diagonal) based on mtDNA sequence data. Pairs statistically significant after sequential Bonferroni correction are indicated by " + " $(p<0.05)$; not significant pairs are indicated by "-".

\begin{tabular}{ccccccccccccccccccc}
\hline & CHI & MOM & ISA & ISB & ADA & ADB & KAM & TAK & KUS & ANE & INU & ECH & YAS & AMA & GOI & FUJ \\
\hline Chinai R. & & + & - & - & + & + & + & - & - & - & + & + & + & + & - & + \\
Momose R. & 1.000 & & + & + & - & - & - & - & - & - & + & + & + & - & + & + & + \\
A population of Ishida R. & 0.000 & 1.000 & & - & + & + & + & - & + & + & + & + & + & + & - & + \\
B population of Ishida R. & 0.000 & 1.000 & 0.000 & & + & + & + & - & + & + & + & + & + & + & - & + \\
A population of Ado R. & 1.000 & 0.000 & 1.000 & 1.000 & & - & - & - & - & - & - & - & - & - & + & + \\
B population of Ado R. & 1.000 & 0.000 & 1.000 & 1.000 & 0.000 & & - & - & - & - & - & - & - & - & + & + \\
Kamo R. & 1.000 & 0.000 & 1.000 & 1.000 & 0.000 & 0.000 & & - & - & - & - & - & - & - & - & - & + & + \\
Takatoki R. & 0.624 & 0.297 & 0.647 & 0.636 & 0.285 & 0.285 & 0.285 & & - & - & - & - & - & - & - & + \\
Kusano R. & 0.503 & 0.303 & 0.528 & 0.516 & 0.292 & 0.292 & 0.292 & -0.058 & & - & - & - & - & - & - & + \\
Ane R. & 0.440 & 0.636 & 0.468 & 0.455 & 0.625 & 0.625 & 0.625 & 0.280 & 0.146 & & - & - & - & - & - & - \\
Inukami R. & 0.800 & 0.131 & 0.815 & 0.808 & 0.122 & 0.122 & 0.122 & -0.032 & 0.020 & 0.397 & & - & - & - & + & + \\
Echi R. & 0.811 & 0.109 & 0.825 & 0.818 & 0.100 & 0.100 & 0.100 & 0.195 & 0.219 & 0.498 & 0.093 & & + & - & + & + \\
Yasu R. & 0.958 & 0.013 & 0.962 & 0.960 & 0.007 & 0.007 & 0.007 & 0.242 & 0.258 & 0.586 & 0.088 & 0.078 & & + & + & + \\
Amasu R. & 1.000 & 0.000 & 1.000 & 1.000 & 0.000 & 0.000 & 0.000 & 0.272 & 0.280 & 0.613 & 0.111 & 0.091 & 0.000 & & + & + \\
Goi R. & 0.000 & 1.000 & 0.000 & 0.000 & 1.000 & 1.000 & 1.000 & 0.612 & 0.489 & 0.424 & 0.791 & 0.803 & 0.956 & 1.000 & & + \\
Fujiko R. & 1.000 & 1.000 & 1.000 & 1.000 & 1.000 & 1.000 & 1.000 & 0.800 & 0.685 & 0.328 & 0.887 & 0.875 & 0.974 & 1.000 & 1.000 \\
\hline
\end{tabular}

Table 5. Hierarchical analysis of molecular variance (AMOVA) for white-spotted charr in and around the Lake Biwa water system.

\begin{tabular}{crccc}
\hline Source of variation & d.f. & Sum of squares & $\begin{array}{c}\text { Variance } \\
\text { components }\end{array}$ & $\begin{array}{c}\text { Percentage of } \\
\text { variation }\end{array}$ \\
\hline Among regions & 3 & 40.22 & 0.195 & $28.39^{*}$ \\
Among populations within regions & 12 & 49.41 & 0.325 & $47.24 * *$ \\
Within populations & 179 & 30 & 0.168 & $24.37^{* *}$ \\
Total & 194 & 86.97 & 0.687 & \\
\hline
\end{tabular}

$*, p<0.05$;**, $p<0.01$

between populations (Table 4). AMOVA showed that $28.39 \%$ of the genetic variance was distributed among regions, $47.24 \%$ among populations within regions, and $24.37 \%$ within populations (Table 5).

\section{DISCUSSION}

\section{Origin and dispersal process}

Hap-19 and its derivative Hap-18 were distributed widely in the Lake Biwa water system and the adjacent inlet rivers of the Sea of Japan, but were not detected in the inlet rivers on the Pacific Ocean side of central Honshu Island (Yamamoto et al., 2004a). Although Hap-18 was detected only in the Ane River of the Lake Biwa water system in a previous study (Yamamoto et al., 2004a), it was detected not only in the Lake Biwa water system but also the adjacent inlet river of the Sea of Japan in this study. Because the white-spotted charr is a northern-temperate salmonid distributed throughout Far Eastern Asia (Kawanabe, 1989), we hypothesize that Hap-19 and Hap-18 dispersed into the northern inlet rivers of Lake Biwa from the adjacent inlet rivers of the Sea of Japan by watershed exchanges, colonizing the whole of the Lake Biwa water system. The loach (Cobitis taenis) provides another piece of evidence that gene flow has occurred across the watershed between the inlet rivers of the Sea of Japan and the inlet rivers of Lake Biwa (Kimizuka and Kobayashi, 1983).

Matsuura (1999) examined the valley formation of the inlet rivers of Lake Biwa and the adjacent inlet rivers of the Sea of Japan, and suggested that these two drainages were connected at some time during the late Pleistocene.
Yamamoto et al. (2004a) hypothesized that in the glacial periods of the Pleistocene, access to and use of loweraltitude habitats could have been possible even in the southern populations as thermal barriers occurred further downstream. Therefore, in the glacial periods of the Pleistocene, Hap-19 and Hap-18 dispersed across the watershed not only through connections of the river systems of Lake Biwa but also through littoral waters of Lake Biwa, enabling them to colonize the whole Lake Biwa water system.

In contrast, Hap-33 and Hap-34 were detected only in the Yasu River population and in the three populations in the Ibuki Mts. Hap-33 and Hap-34 may have arisen in the Lake Biwa water system or dispersed into this system from the adjacent rivers of the Pacific Ocean by watershed exchange. These inferences about Hap-33 and Hap-34 may need confirmation by further studies including additional collections, particularly from the Ibi River system, because there is growing evidence of genetic differentiation between the eastern and western flanks of the Ibuki and Suzuka Mts. in various species of freshwater fishes, e.g., medaka, Oryzias latipes (Sakaizumi et al., 1983); the freshwater goby Rhinogobius flumineus (Shimizu et al., 1993); Japanese bagrid catfishes (Watanabe and Nishida, 2003); and the freshwater threespine stickleback, hariyo (Watanabe et al., 2003).

\section{Difference in mtDNA diversity between the western and eastern parts of the Lake Biwa water system}

The white-spotted charr populations in the western part of the Lake Biwa water system showed lower mtDNA diver- 
sity than in the eastern. The smaller census population size in the western inlet rivers of Lake Biwa compared with the eastern, owing to shortness of the western inlet rivers except for the Ado River (Kikko et al., unpublished data), might be a cause of the loss of genetic diversity through genetic drift. On the other hand, because the white-spotted charr is adapted to cold-water habitats, its distribution is restricted to higher altitudes in the southern regions of its range (Nakano et al., 1996). However, higher altitude ranges (over $500 \mathrm{~m}$ ) in the Nosaka and Hira Mts. in the western part of the Lake Biwa water system $\left(310 \mathrm{~km}^{2}\right.$; Fig. 1) are smaller in area than in the Ibuki and Suzuka Mts. in the eastern part of the system $\left(540 \mathrm{~km}^{2}\right.$; Fig. 1). Therefore, white-spotted charr populations in the western part of the Lake Biwa water system might have suffered more habitat reduction in the postglacial warming.

This difference in diversity was not detected by AFLP analysis (nucleotide diversity $0.075-0.119 \%$ in the western inlet rivers of Lake Biwa; $0.067-0.146 \%$ in the eastern inlet rivers of Lake Biwa; Kikko et al., 2008a). Theoretically, mtDNA has an effective population size one quarter of that of nuclear loci and is thus more susceptible to the influence of genetic drift (Hinten et al., 2003). Such genetic drift of mtDNA haplotypes in small salmonid populations has actually been reported, although temporal stability has been observed for nuclear allele frequencies (Hansen and Loeschcke, 1996; Laikre et al., 1998).

\section{Population genetic structure}

The high overall $F_{\mathrm{ST}}$ estimate $(0.50)$, together with the pairwise comparisons of $F_{\mathrm{ST}}$, indicated significant genetic divergence between populations. Our samplings were conducted in the headwater reaches of small tributaries to exclude stocked fish. Thus, isolation and the relatively small population sizes of above-barrier populations would probably have led to reduced genetic diversity and strong differentiation from other populations. High levels of $F_{\mathrm{ST}}$ have been observed in other salmonid species where there are numerous restrictions to movement between populations (Bouza et al., 1999; Costello et al., 2003; Yamamoto et al., 2004b).

AMOVA indicated that $28.39 \%$ of the genetic variation in white-spotted charr mtDNA in and around the Lake Biwa water system was distributed among regions, $47.24 \%$ among populations within regions, and $24.37 \%$ within populations. Genetic variation was thus more pronounced among regions and among populations within regions than within populations. A plausible explanation for the substantial proportion of molecular variation among populations within regions (47.24\%) might be related to the reduced gene flow among populations as well as small population size in postglacial warming periods, because the distribution of white-spotted charr is restricted to higher altitudes in the southern regions of its range (Nakano et al., 1996; Kikko et al., 2008a). Furthermore, each local population among rivers in the Lake Biwa water system was genetically differentiated based on nuclear genome variation detected by AFLP (Kikko et al., 2008a), suggesting the genetic integrity of each population in the system. In addition to genetic divergence based on mtDNA and nuclear genome analysis, some ecological differences have been recognized among populations ana- lyzed in genetic studies, including egg size and growth rate of juveniles (Kikko et al., 2008b), and morphological differentiation such as the body spot pattern in the Ane River system, Lake Biwa basin (Kikko et al., 2007). Therefore, each population should be adequately considered when establishing population units for conservation and management.

Isolated headwater resident populations of salmonids in marginal habitats may represent important sources of genetic diversity that need protection and preservation (Northcote, 1992). This is probably also the case for the white-spotted charr in the Lake Biwa water system. However, some putatively unstocked populations had haplotypes of hatchery-reared charr, indicating that artificial transplantation had been carried out without consideration for the various native populations (Kikko et al., unpublished data). Thus it is necessary not to stock hatchery-reared charr in headwater reaches where native white-spotted charr are present.

\section{ACKNOWLEDGMENTS}

We thank Prof. M. Tanaka and Prof. T. Nakabo (Kyoto University) for offering the opportunity for this study, and Dr. S. Takahashi for encouragement and critical reading of the manuscript. Our special thanks go to T. Tokuhara (Gifu Prefectural Research Institute for Freshwater Fish and Aquatic Environments) for data on stocking history. We also are grateful to the staff at Shiga Prefectural Fisheries Experimental Station for assistance with the field research.

\section{REFERENCES}

Bouza C, Arias J, Castro J, Sanchez L, Martinez P (1999) Genetic structure of brown trout, Salmo trutta L., at the southern limit of the distribution of anadromous form. Mol Ecol 8: 1991-2002

Costello AB, Down TE, Pollard SM, Pacas CJ, Taylor EB (2003) The influence of history and contemporary stream hydrology on the evolution of genetic diversity within species: an examination of microsatellite DNA variation in bull trout, Salvelinus confluentus (Pisces: Salmonidae). Evolution 57: 328-344

Excoffier L, Smouse PE, Quattro JM (1992) Analysis of molecular variance inferred from metric distances among DNA haplotypes: application to human mitochondrial DNA restriction data. Genetics 131: 479-491

Excoffier L, Laval G, Schneider S (2005) Arlequin ver. 3.0: An integrated software package for population genetics data analysis. Evol Bioinform Online 1: 47-50

Felsenstein J (1985) Confidence limits on phylogenies: an approach using the bootstrap. Evolution 39: 783-791

Fujioka Y (2005) White-spotted charr. In "Red Data Book of Shiga Prefecture" Ed by Wildlife Survey Group in Shiga Prefecture, Sunrise Press, Shiga, p 475

Hansen MM, Loeschcke V (1996) Temporal variation in mitochondrial DNA haplotype frequencies in a brown trout (Salmo trutta L.) population that shows stability in nuclear allele frequencies. Evolution 50: 454-457

Hinten GN, Harriss F, Rossetto M, Braverstock PR (2003) Genetic variation and island biogeography: microsatellite and mitochondrial DNA variation in island populations of the Australian bush rat, Rattus fuscipes greyii. Conserv Genet 4: 759-778

Hosoya K (2002) Salmonidae. In "Fishes of Japan with Pictorial Keys to the Species, English Edition" Ed by T Nakabo, Tokai University Press, Tokyo, pp 299-304, 1473-1474

Imanishi K (1967) Genus Salvelinus - distribution in Japan. In "Nature-Ecology" Ed by M Morishita, T Kita, Chuo-koron-sha, Tokyo, pp 3-46

Kawanabe H (1989) Japanese char(r(r))s and masu-salmon problems: a review. Physiol Ecol Japan Spec 1: 13-24 
Kikko T, Sato T, Kano Y, Harada Y, Kai Y (2007) The occurrence and distribution of nagaremon-charr, a morphotype of Salvelinus leucomaenis japonicus, in the Ane River system, Lake Biwa basin. Jpn J Ichthyol 54: 79-85 (in Japanese with English abstract)

Kikko T, Kai Y, Kuwahara M, Nakayama K (2008a) Genetic diversity and population structure of white-spotted charr (Salvelinus leucomaenis) in the Lake Biwa water system inferred from AFLP analysis. Ichthyol Res 55: (in press)

Kikko T, Harada Y, Takeuchi D, Kai Y (2008b) Interpopulation variation in egg size of fluvial white-spotted charr, Salvelinus leucomaenis. Fish Sci 74: (in press)

Kimizuka Y, Kobayashi H (1983) Geographic distributions of karyological races of Cobitis biwae (Cobitididae). Jpn J Ichthyol 30: 308-312

Kubota H, Doi T, Yamamoto S, Watanabe S (2007) Genetic identification of native populations of fluvial white-spotted charr Salvelinus leucomaenis in the upper Tone River drainage. Fish Sci 73: 270-284

Laikre L, Jorde PE, Ryman N (1998) Temporal change of mitochondrial DNA haplotype frequencies and female effective size in a brown trout (Salmo trutta) population. Evolution 52: 910-915

Matsuura T (1999) Process of divide in valley forming in the Nosaka mountains, southwest Japan. Quart J Geogr 51: 179-187 (in Japanese with English abstract)

Nakamura T (2003) Meristic and morphometric variations in fluvial Japanese charr between river systems and among tributaries of a river system. Environ Biol Fish 66: 133-141

Nakano S, Kitano F, Maekawa K (1996) Potential fragmentation and loss of thermal habitats for charrs in the Japanese archipelago due to climatic warming. Freshw Biol 36: 711-722

Naruse T, Yoshiyasu K (1983) Iwana, Salvelinus leucomaenis, from view point of its white spots in head region. In "The Freshwater Fishes" Ed by E Kimura, Tansuigyohogokyoukai, Osaka, pp $109-126$ (in Japanese)

Nei M (1987) Molecular Evolutionary Genetics. Colombia University Press, New York
Northcote TG (1992) Migration and residency in stream salmonidssome ecological considerations and evolutionary consequences. Nordic J Freshw Res 67: 5-17

Sakaizumi M, Moriwaki K, Egami N (1983) Allozymic variation and regional differentiation in wild populations of the fish Oryzias latipes. Copeia 1983: 311-318

Shimizu T, Taniguchi N, Mizuno N (1993) An electrophoretic study of genetic differentiation of a Japanese freshwater goby, Rhinogobius flumineus. Jpn J Ichthyol 39: 329-343

Swofford DL (2000) PAUP*: Phylogenetic Analysis Using Parsimony (*and Other Methods) Version 4. Sinauer Associates, Sunderland, MA

Thompson JD, Higgins DG, Gibson TJ (1994) CLUSTAL W: improving the sensitivity of progressive multiple sequence alignment through sequence weighting, position-specific gap penalties and weight matrix choice. Nucleic Acids Res 22: 4673-4680

Watanabe K, Nishida M (2003) Genetic population structure of Japanese bagrid catfishes. Ichthyol Res 50: 140-148

Watanabe K, Mori S, Nishida M (2003) Genetic relationships and origin of two geographic groups of the freshwater threespine stickleback, 'Hariyo'. Zool Sci 20: 265-274

Wright S (1969) Evolution and Genetics of Populations Vol 2, The Theory of Gene Frequencies. University of Chicago Press, Chicago

Yamamoto S, Kohara M, Sawamoto Y, Tsukisaka M (2000) Variation of spots in Japanese char Salvelinus leucomaenis in the rivers of Nagano Prefecture, Japan. Bull Nagano Pref Fish Exp Stn 4: 16-23 (in Japanese)

Yamamoto S, Morita K, Kitano S, Watanabe K, Koizumi I, Maekawa K, Takamura K (2004a) Phylogeography of white-spotted charr (Salvelinus leucomaenis) inferred from mitochondrial DNA sequences. Zool Sci 21: 229-240

Yamamoto S, Morita K, Koizumi I, Maekawa K (2004b) Genetic differentiation of white-spotted charr (Salvelinus leucomaenis) populations after habitat fragmentation: spatial-temporal changes in gene frequencies. Conserv Genet 5: 529-538

(Received January 6, 2007 / Accepted October 9, 2007) 